\title{
Analysis of Membrane Reactors for Integrated Coupling of Oxidative and Thermal Dehydrogenation of Propane
}

\author{
Andreas Brune ${ }^{1,3 *}$, Tanya Wolff ${ }^{2}$, Andreas Seidel-Morgenstern ${ }^{1,2}$ and Christof Hamel ${ }^{1,3}$
}

\begin{abstract}
This study presents strategies capable to intensify the thermal dehydrogenation of propane (TDH) using integrated reactor concepts. An inert packed bed membrane reactor for distributed dosing of oxygen to realize the oxidative dehydrogenation $(\mathrm{ODH})$ was studied and compared to a reactor with catalytically active membrane. The latter concept allows to combine TDH and ODH in one apparatus to overcome the chemical equilibrium by in-situ conversion of the by-product $\mathrm{H}_{2}$ using $\mathrm{O}_{2}$ or in a reverse water-gas shift reaction by $\mathrm{CO}_{2}$. If $\mathrm{CO}_{2}$ is used as active sweep gas the reactor offered better performance regarding yield and selectivity. Strategies for further thermal integration are discussed.
\end{abstract}

\section{Keywords}

Membrane reactor, Dehydrogenation, Process intensification, Heterogeneous catalysis, Multifunctional reactor

\section{Introduction}

A challenge in chemical engineering is the optimization of processes with respect to the reactor performance (productivity, yield) as well as economic factors such as investment and operating costs. A promising approach to optimize these parameters is process intensification applying multifunctional reactors [1, 2]. In a multifunctional reactor the reaction is enhanced by the integration of one or more additional unit operations in the same apparatus e.g. separation of products and by-products or heat exchange [2]. In this way it is possible to provide advantageous temperature or concentration profiles in order to optimize reaction rates and selectivity.

Numerous research activities in the field of process intensification are connected to membrane reactors, which allow to combine a chemical reaction with a simultaneous extraction of intermediates or products and a distribution of reactants, respectively [3]. Different setups are possible with respect to the function of the membrane, e.g. membrane distributors and extractors [4]. Membranes can be categorized as selective, nonselective and catalytically active [5].

The dehydrogenation of propane is chosen as a model reaction for this study. The on-purpose dehydrogenation of propane has a growing relevance in industry [6]. Around $80 \%$ of the market is still served by propylene produced as a by-product in traditional processes as pyrolysis and catalytic cracking of hydrocarbons [7]. Because of a shift in the supply of cracking feedstock and a growing demand of on-purpose production a further intensification of these processes is of increasing importance. Today's industrial processes are based on the highly endothermic thermal dehydrogenation reaction $\left(\Delta_{\mathrm{R}} H=124 \mathrm{~kJ} \mathrm{~mol}^{-1}\right.$, Catofin, Oleflex, Star, FBD, PDH) [6, 7] (Eq. (1)).

$$
r_{1}: \quad C_{3} H_{8} \rightleftharpoons C_{3} H_{6}+H_{2}
$$

\footnotetext{
${ }^{1}$ Andreas Brune (andreas.brune@ovgu.de), Prof. Andreas Seidel-Morgenstern, Prof. Christof Hamel, Otto von Guericke University Magdeburg, Institute of Process Engineering, Universitätsplatz 2, 39106 Magdeburg, Germany.

2 Dr. Tanya Wolff, Prof. Andreas Seidel-Morgenstern, Max Planck Institute for Dynamics of Complex Technical Systems, Sandtorstraße 1, 39106, Magdeburg, Germany.

${ }^{3}$ Andreas Brune, Prof. Christof Hamel,

Anhalt University of Applied Sciences, Process Engineering, Bernburger Straße 55, 06354, Köthen, Germany.
} 
The catalysts used in these processes provide a high selectivity but need to be regenerated regularly because of rapid deactivation due to coking [8]. Furthermore, the thermal dehydrogenation (TDH) is limited by chemical equilibrium. Efficient $\mathrm{H}_{2}$ conversion or removal seems to be promising. Examples for enhancing this reaction using membranes can be found in recent literature. Theoretical studies [911] and experimental contributions [12] mainly discuss the separation of hydrogen to overcome the reaction equilibrium exploiting selective and cost-intensive Pd membranes.

An alternative reaction is the oxidative dehydrogenation (ODH) (Eq. (2)).

$$
r_{2}: \quad \mathrm{C}_{3} \mathrm{H}_{8}+0.5 \mathrm{O}_{2} \rightleftharpoons \mathrm{C}_{3} \mathrm{H}_{6}+\mathrm{H}_{2} \mathrm{O}
$$

The $\mathrm{ODH}$ is not limited by chemical equilibrium. It is an exothermic reaction $\left(\Delta_{\mathrm{R}} H=-118 \mathrm{~kJ} \mathrm{~mol}^{-1}\right)$ that proceeds at lower temperatures than the TDH and in the presence of oxygen. That prevents coking, whereas the selectivity is significantly lower due to unwanted side reactions like total and partial oxidations [13]. Experimental work on this reaction with respect to selective [14, 15] and non-selective membranes [16] has been conducted. A reaction network including total and partial oxidation has been suggested [17, 18] (Fig. 1).

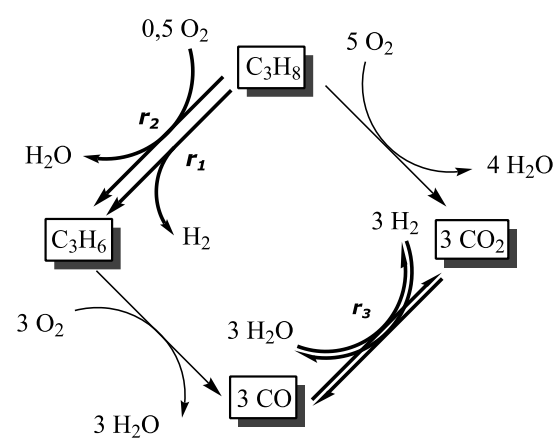

Figure 1: Reaction network of the ODH and TDH [17].

By coupling the reactions thermally, the heat that is produced by the ODH is directly used to compensate the heat requirements of the TDH in order to reduce the energy consumption of the whole process. Thermal coupling in one apparatus provides better efficiency in comparison to external heat exchange but limits the degrees of freedom available to control the process [19]. The concept of thermal coupling of endothermic and exothermic reactions in membrane reactors has been studied by different groups for steam reforming and partial oxidation of methane [20-22].

\section{Aim and Analyzed Concepts}

Aim of this study is to increase selectivity and conversion of the on-purpose propene production via $\mathrm{ODH}$ and TDH by combining these two reactions in one membrane reactor. The coupling of both reactions can lead to higher efficiency. For this reason, the following concepts have been studied:

a) As reference concept the well-established fixed bed reactor (FBR) was used for the ODH of propane on a $\mathrm{VO}_{x}$ catalyst (Fig. 2a). It is based on dosing all reactants in a co-feed mode.

b) Studies revealed that, due to unwanted parallel and side reactions, a distributed dosing of oxygen is beneficial [23-25]. For that reason, initially an inert packed bed membrane reactor (PBMR) for a distributed dosing and lowering $\mathrm{O}_{2}$ on $\mathrm{VO}_{x}$ is considered (Fig. 2b) [16, 26, 27].

c) Furthermore, the ODH has been performed in a packed bed catalytic membrane reactor (PBCMR). A catalytically active membrane $\left(\mathrm{VO}_{\mathrm{x}}\right)$ was combined with a fixed bed realized in a dead-end configuration (Fig. 2c). The dead-end distributor configuration allows to control the crossmembrane flux of $\mathrm{O}_{2}$ and $\mathrm{CO}_{2}$ combining TDH and reverse water-gas shift reaction (Eq. (3)) to remove hydrogen and to overcome the chemical equilibrium. 
d) Besides the dead-end configuration, a PBCMR can be used with an open-end (Fig. 2d). In that extractor configuration, the reactive sweep gas $\mathrm{CO}_{2}$ can also be used to overcome the equilibrium of the TDH by removing the hydrogen via reverse water-gas shift reaction (Eq. (3)).

$$
r_{3}: \mathrm{CO}_{2}+\mathrm{H}_{2} \rightleftharpoons \mathrm{CO}+\mathrm{H}_{2} \mathrm{O}
$$

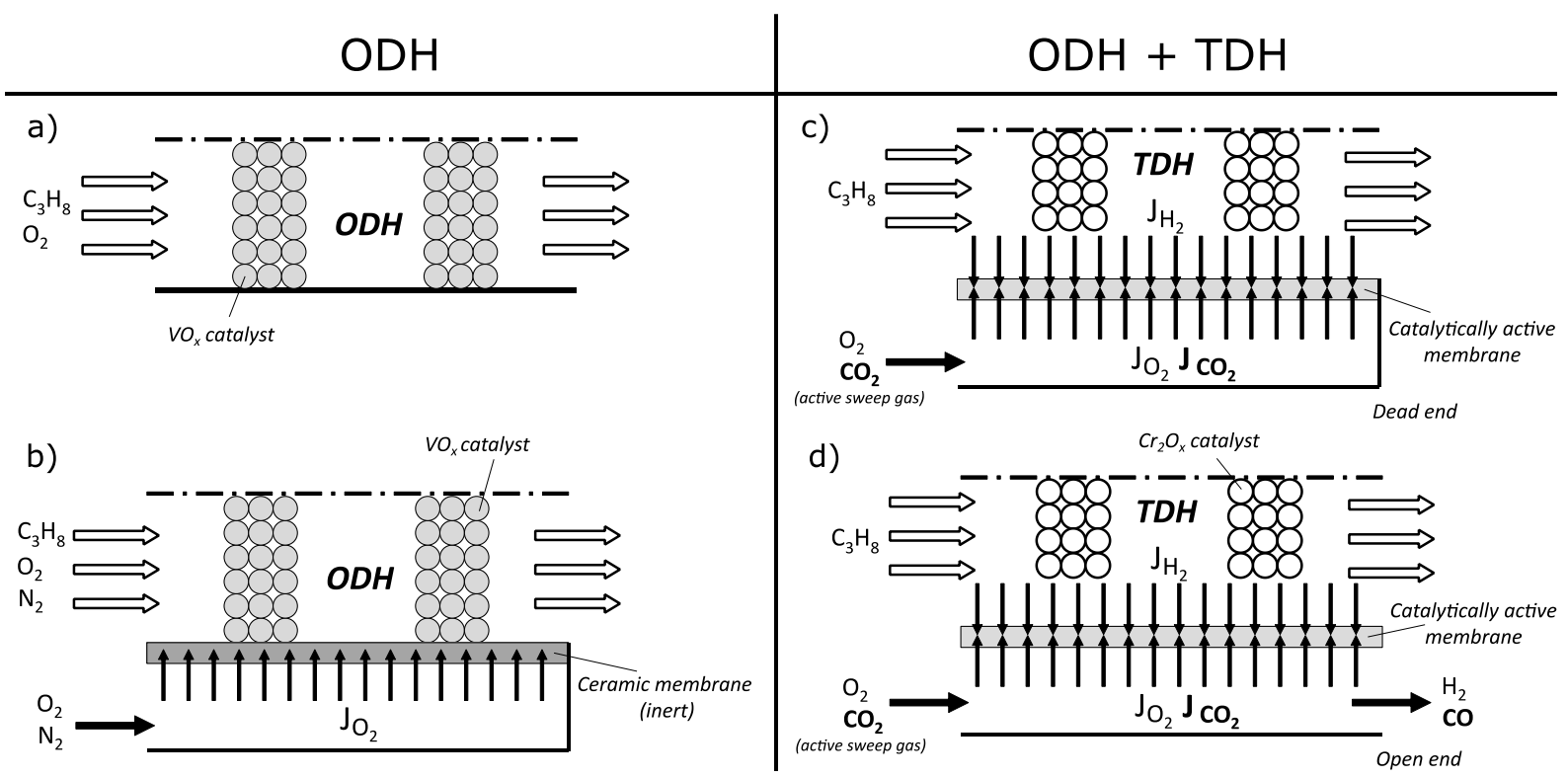

Figure 2: Different reactor concepts: a) fixed bed reactor (FBR), b) packed bed membrane reactor (PBMR), c) packed bed catalytic membrane reactor (PBCMR) in dead end configuration (distributor, $\left.\mathrm{O}_{2}\right)$, d) packed bed catalytic membrane reactor $(P B C M R)$ in open-end configuration (extractor) using i.a. active sweep gas $\mathrm{CO}_{2}$.

\section{Experimental}

\section{Catalyst Preparation and Membrane}

The inert $\mathrm{y}-\mathrm{Al}_{2} \mathrm{O}_{3}$ membrane used in this study, provided by Fraunhofer Institute for Ceramic Technologies and Systems IKTS, has a length of $350 \mathrm{~mm}$ and an inner diameter/outer diameter of $21 / 32 \mathrm{~mm}$. The permeable zone of the membrane is $104 \mathrm{~mm}$ long. For FBR experiments a completely vitrified membrane was used to provide the same heat transfer compared to PBMR. Transport properties and compatibility of membrane and reaction have been investigated in previous studies [28].

For ODH a vanadium oxide $\left(\mathrm{VO}_{\mathrm{x}}\right)$ catalyst was used (configuration $\left.\left.\mathrm{a}\right)+\mathrm{b}\right)$ ). The catalyst was prepared via impregnation of $\mathrm{y}-\mathrm{Al}_{2} \mathrm{O}_{3}$ spheres (diameter: $1 \mathrm{~mm}$, specific area: $168 \mathrm{~m}^{2} \mathrm{~g}^{-1}$ ) with vanadyl acetylacetonate in acetone. The impregnated catalyst was washed, dried and calzinated. The vanadium content of the catalyst was $1.4 \%$ and its specific area $158 \mathrm{~m}^{2} \mathrm{~g}^{-1}$ (BET) $[26,27,29]$. A chromium catalyst (configuration c) + d)) was also prepared via impregnation of $\mathrm{\gamma}-\mathrm{Al}_{2} \mathrm{O}_{3}$ support $\left(1.8 \mathrm{~mm}, 200 \mathrm{~m}^{2} \mathrm{~g}^{-1}\right)$ with chromium nitrate nonahydrate in water and is characterized by a chromium content of $5.8 \%$ and a specific area of $178 \mathrm{~m}^{2} \mathrm{~g}^{-1}$.

Since the membrane itself is catalytically not active in strategy a) and b), the raw membranes had to be activated for strategies $\mathrm{c}$ ) and d) by deposition of $\mathrm{VO}_{\mathrm{x}}$ on its surface. In analogy to the catalysts the membrane was activated using the impregnation method.

\section{Setup and Experimental Procedures}

The experimental setup consists of a pilot plant scale reactor module with catalytic afterburner. The membrane was installed in a stainless steel housing (inner diameter: $38.4 \mathrm{~mm}$ ) including heating sleeve 
control. Analysis of gas flows was realized using an online GC-MSD system (Agilent 6890GC with 5973 MSD). In the given setup it was possible to take samples of the gas phase at the inlet and the outlet of the reactor (tube side). In runs with the PBMR and PBCMR, samples were also taken at the shell side. All gas flows were controlled by mass flow controllers (Bürkert). The whole pilot plant was automated by Simatic S7 (Siemens). The experimental procedures are described by Hamel et al. [26, 27].

For safety reasons the concentrations of hydrocarbons and oxygen were limited to lower explosion limits. The mixtures were diluted with nitrogen. The inlet concentration of propane at FBR (configuration a)) was set to $1 \%$. Propane concentration in PBMR (configuration b)) was set to $1 \%$ with respect to the overall volumetric flow. The ratio between propane and oxygen of 1 was adjusted. The weight hourly space velocity (WHSV = mass of catalyst/total volumetric flow rate) was $100 \mathrm{~kg} \mathrm{~s} \mathrm{~m}^{-3}$ or $400 \mathrm{~kg} \mathrm{~s} \mathrm{~m}^{-3}$, respectively. For the PBMR measurements, the ratio of the volumetric flow between the tube side and the shell side (TS/SS) was set to 8 . Thus $88 \%$ of the overall volumetric flow is fed to the reactor via the membrane.

In PBCMR experiments the catalytically active membrane $\left(\mathrm{VO}_{\mathrm{x}}\right)$ has been filled with particular $\mathrm{Cr}_{2} \mathrm{O}_{3}$ catalyst (config. c) + d)) to combine TDH, ODH and reverse water-gas shift reaction. Experiments with catalytically active membrane have been conducted with $0.3 \% \mathrm{O}_{2}$ in dead-end (distributor) and openend (extractor) configurations. Besides that, $\mathrm{CO}_{2}$ has been utilized as an active sweep gas. In extractor as well as distributor configurations $2 \% \mathrm{CO}_{2}$ have been used. In setups using catalytically active membrane, a WHSV of $400 \mathrm{~kg} \mathrm{~s} \mathrm{~m}^{-3}$ has been tested. In all experiments the reactor was heated by electric heating sleeves. To guarantee reproducibility at least three measurements have been carried out in a temperature range between $350^{\circ} \mathrm{C}$ and $550^{\circ} \mathrm{C}$.

\section{Results}

\section{PBMR vs FBR}

Fig. 3 reveals the performance of the FBR (config. a)) in comparison to the PBMR (config. b)) at different temperatures and volumetric flow rates. The conversion increases in FBR as well as PBMR with increasing temperature (Fig. 3a). An increase of temperature also leads to a decrease in selectivity because undesired parallel and consecutive side reaction are more pronounced at higher temperatures. Fig. $3 \mathrm{~b}$ shows that a PBMR with $\mathrm{O}_{2}$ dosing outperforms the FBR at high temperatures in terms of selectivity. That results in a higher yield for the PBMR especially at long contact times (Fig 3c). The maximum yield of $7.4 \%$ is taken as a reference for the evaluation of the following concepts (Fig 3c).
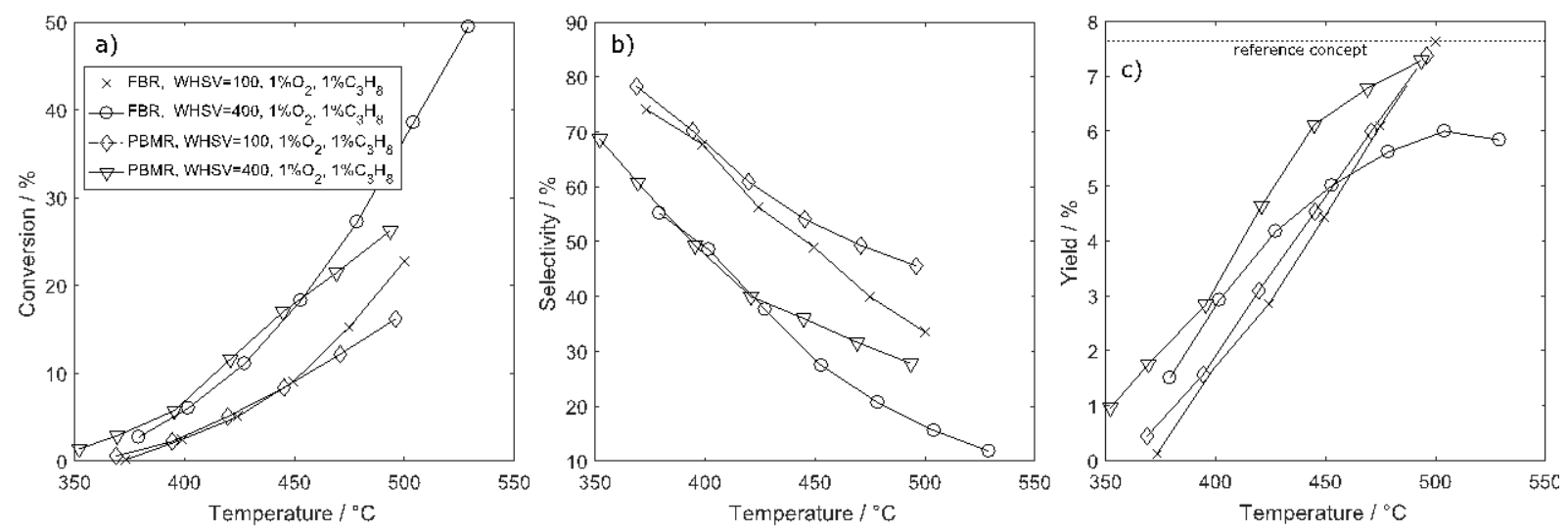

Figure 3: Comparison of FBR and PBMR at different temperatures and WHSV of 100 and $400 \mathrm{~kg} \mathrm{sm}^{-3}\left(x_{\mathrm{C} 3 \mathrm{H} 8}=1 \%, x_{02}=1 \%\right.$, $P B M R: T S / S S=8$ ). 


\section{Distributor vs Extractor Using $\mathrm{CO}_{2}$ as Active Sweep Gas}

In comparison to the conventional FBR and the inert PBMR, a new PBCMR setup consisting of an additional catalytically active membrane in distributor (config. a) and extractor configuration (config. d)) has been analyzed. The results given in Fig. 4 indicate a better performance of the strategies $c)+d$ ) compared to the conventional FBR and the PBMR. The conversion of propane is as high as in the alternatives (Fig. 4a) but the selectivity increases significantly with increasing temperature (Fig. 4b). That leads to a better yield especially at higher temperatures (Fig. 4c). The use of $\mathrm{CO}_{2}$ as an active sweep gas seems to be particularly promising in order to overcome limitations by chemical equilibrium in the reverse water-gas shift reaction. With $24.4 \%$ the yield of the extractor setup (config. d)) with $\mathrm{CO}_{2}$ as an active sweep gas performs best and tripled the yield of the reference concept. Without an active sweep gas, the yields are still substantially higher than in the other concepts.
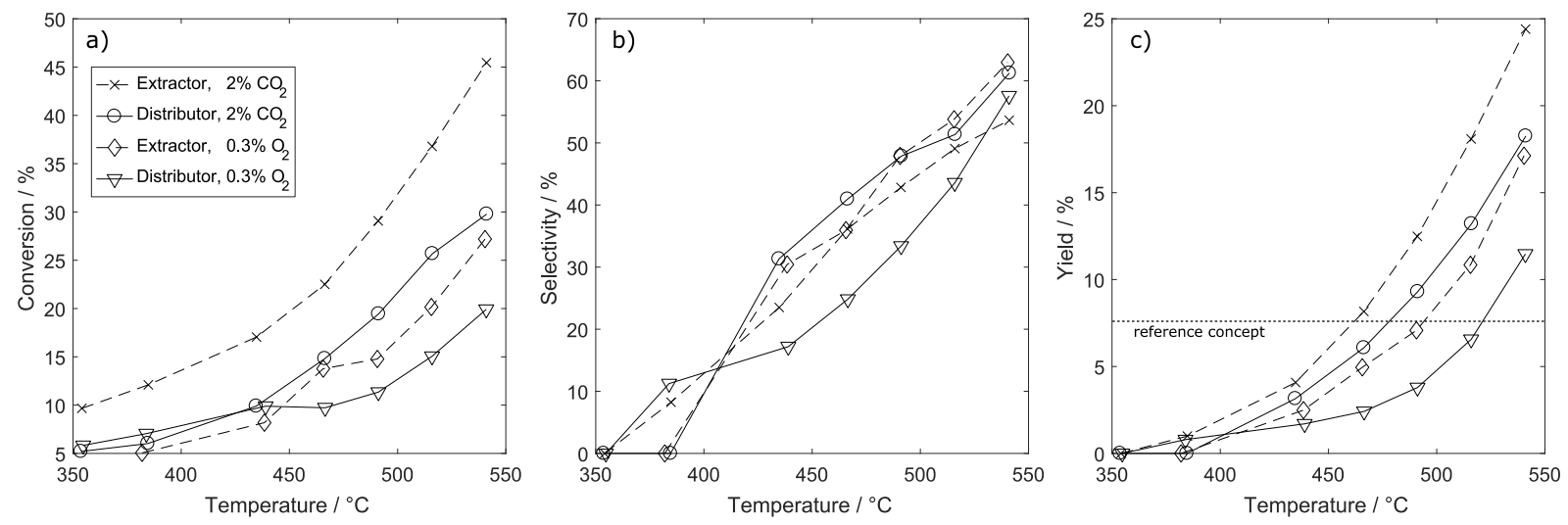

Figure 4: Comparison of extractor and distributor setup at different temperatures and WHSV of $400 \mathrm{~kg} \mathrm{~s} \mathrm{~m}^{-3}\left(x_{\mathrm{C} 3 \mathrm{H}}=1 \%\right.$, PBMR: TS/SS=8).

\section{Conclusion}

Subject of this study was the ODH of propane, which is not commercially realized yet, due to low yield and selectivity. It has been shown that the distributed dosing of oxygen allows to perform this reaction in a more efficient than in an FBR especially for long contact times. Yields up to $7.4 \%$ were achieved with these setups.

Based on these findings an instructive combination of thermal and oxidative dehydrogenation in one apparatus has been tested. Yields have been more than tripled by using integrated concepts with active membranes. The distributor and the extractor setups offered yields of $18.3 \%$ and $24.4 \%$, respectively, utilizing $\mathrm{CO}_{2}$ as an active sweep gas. Formed $\mathrm{H}_{2}$ in TDH could be converted with $\mathrm{CO}_{2}$ in order to shift the chemical equilibrium to enhance conversion and yield. Thus, the process can serve as a $\mathrm{CO}_{2}$ sink, which is beneficial from an environmental point of view. Clearly, the combination of an exothermic and an endothermic reaction reveals advantages due to thermal integration and can help to reduce energy costs.

Different options of coupling of ODH and TDH in one apparatus are promising approaches.

\section{Outlook}

In analogy to the integrated reactor concepts shown in Fig. 2 a periodically operating reactor setup including two fixed beds is imaginable. The option presented in Fig. 5 seems to be promising since a mass and thermal coupling in one apparatus can be realized. The major drawback of this option is the rapid coking of the TDH catalyst (phase 1). This problem could be solved by flow reversal within the reactor to burn off the coke at the tube side and perform the TDH at the shell side during reaction (phase 2). Such a periodically operated system is seen as attractive. 


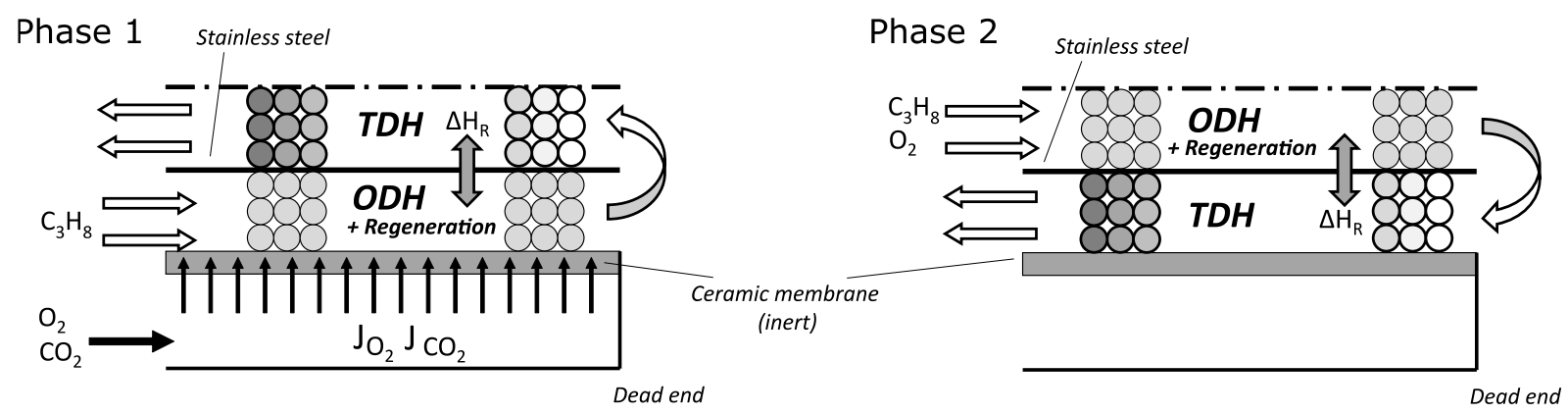

Figure 5: Periodically operating reactor concept combining the ODH and TDH with regeneration of the coked catalyst.

Besides an experimental and model based analysis future work in this area will be focused on the investigation of coking and regeneration kinetics.

\section{Acknowledgement}

The financial support of the German Science Foundation (projects: „Kontrolle und Intensivierung von Reaktionen durch Einsatz zyklisch betriebener Distributoren“ (SE 568/23-1 / HA 6762/2-1) and SFB/TRR 63: "InPROMPT - Integrated Chemical Processes in Multi-Phase Fluid Systems") is gratefully acknowledged.

\section{Symbols}

$\Delta_{\mathrm{R}} \mathrm{H} \quad\left[\mathrm{kJ} \mathrm{mol}{ }^{-1}\right] \quad$ standard enthalpy of reaction

$x \quad[-] \quad$ mole fraction

TS/SS [ - ] ratio of volumetric flow rate at tube side and shell side

WHSV $\left[\mathrm{kg} \mathrm{s} \mathrm{m}^{-3}\right] \quad$ weight hourly space velocity

$\begin{array}{ll}\text { Abbreviations } & \\ \text { FBR } & \text { fixed bed reactor } \\ \text { ODH } & \text { oxidative dehydrogenation } \\ \text { PBCMR } & \text { packed bed catalytic membrane reactor } \\ \text { PBMR } & \text { packed bed membrane reactor } \\ \text { TDH } & \text { thermal dehydrogenation }\end{array}$

\section{References}

[1] F. M. Dautzenberg, M. Mukherjee, Chem. Eng. Sci. 2001, 56 (2), 251 - 267.

DOI: 10.1016/S0009-2509(00)00228-1.

[2] D. W. Agar, Chem. Eng. Sci. 1999, 54 (10), 1299 - 1305. DOI: 10.1016/S0009-2509(99)00040-8.

[3] R. Dittmeyer, J. Caro, in Handbook of Heterogeneous Catalysis, Vol. 10 (Eds: G. Ertl, H. Knözinger, F. Schüth, J. Weitkamp), Wiley-VCH Verlag GmbH \& Co. KGaA. Weinheim, Germany 2008. 
[4] J. Caro, in Comprehensive membrane science and engineering (Eds: E. Drioli), Elsevier. Amsterdam 2010.

[5] R. Dittmeyer, V. Höllein, K. Daub, J. Mol. Catal. A: Chem. 2001, 173 (1-2), 135 - 184. DOI: 10.1016/S1381-1169(01)00149-2.

[6] P. Eisele, R. Killpack, in Ullmann's encyclopedia of industrial chemistry, Vol. 82, Wiley. Chichester 2010.

[7] A. V. Lavrenov, L. F. Saifulina, E. A. Buluchevskii, E. N. Bogdanets, Catal. Ind. 2015, 7 (3), 175 - 187. DOI: 10.1134/S2070050415030083.

[8] J. Gascón, C. Téllez, J. Herguido, M. Menéndez, Appl. Catal., A 2003, 248 (1-2), 105 - 116. DOI: 10.1016/S0926-860X(03)00128-5.

[9] S.-W. Choi, D. S. Sholl, S. Nair, J. S. Moore, Y. Liu, R. S. Dixit, J. G. Pendergast, AIChE J. 2017, 63 (10), 4519 - 4531. DOI: 10.1002/aic.15785.

[10] M. Sheintuch, O. Nekhamkina, Chem. Eng. J. 2018, 347, 900 - 912. DOI: 10.1016/j.cej.2018.04.137.

[11] E. V. Shelepova, A. A. Vedyagin, I. V. Mishakov, A. S. Noskov, Int. J. Hydrogen Energy 2015, 40 (8), 3592 - 3598. DOI: 10.1016/j.ijhydene.2014.09.004.

[12] A. Ricca, V. Palma, G. Iaquaniello, E. Palo, A. Salladini, Chem. Eng. J. 2017, 330, 1119- 1127. DOI: 10.1016/j.cej.2017.08.064.

[13] H. Asadi-Saghandi, J. Karimi-Sabet, Korean J. Chem. Eng. 2017, 34 (7), 1905 - 1913. DOI: 10.1007/s11814-017-0025-1.

[14] H. Wang, Y. Cong, W. Yang, Chem. Commun. 2002 (14), 1468 - 1469. DOI: 10.1039/b203168j.

[15] W. Yang, H. Wang, X. Zhu, L. Lin, Top Catal 2005, 35 (1-2), 155 - 167. DOI: 10.1007/s11244005-3820-6.

[16] R. Ramos, M. Menéndez, J. Santamaría, Catal. Today 2000, 56 (1-3), 239 - 245. DOI: 10.1016/S0920-5861(99)00281-3.

[17] C. Liebner, Einführung der Polythermen Temperatur Rampen Methode für die Ermittlung kinetischer Daten, Ph.D. Thesis, Technische Universität Berlin 2003.

[18] C. Hamel, Á. Tóta, F. Klose, E. Tsotsas, A. Seidel-Morgenstern, in Membrane reactors: Distributing reactants to improve selectivity and yield (Eds: A. Seidel-Morgenstern), Wiley-VCH Verlag GmbH \& Co. Weinheim 2010.

[19] G. Eigenberger, G. Kolios, U. Nieken, Chem. Eng. Sci. 2007, 62 (18-20), 4825 - 4841. DOI: 10.1016/j.ces.2007.02.039.

[20] K. Patel, A. Sunol, Int. J. Hydrogen Energy 2007, 32 (13), $2344-2358$. DOI: 10.1016/j.ijhydene.2007.03.004.

[21] D. S. A. Simakov, M. Sheintuch, Ind. Eng. Chem. Res. 2010, 49 (3), 1123 - 1129. DOI: 10.1021/ie900938n.

[22] Y. Wei, W. Yang, J. Caro, H. Wang, Chem. Eng. J. 2013, 220, 185- 203. DOI: 10.1016/j.cej.2013.01.048.

[23] C. Hamel, S. Thomas, K. Schädlich, A. Seidel-Morgenstern, Chem. Eng. Sci. 2003, 58 (19), 4483 - 4492. DOI: 10.1016/S0009-2509(03)00308-7.

[24] J. Caro, K. J. Caspary, C. Hamel, B. Hoting, P. Kölsch, B. Langanke, K. Nassauer, T. Schiestel, A. Schmidt, R. Schomäcker, A. Seidel-Morgenstern, E. Tsotsas, I. Voigt, H. Wang, R. Warsitz, S. Werth, A. Wolf, Ind. Eng. Chem. Res. 2007, 46 (8), 2286 - 2294. DOI: 10.1021/ie0609620.

[25] O. Czuprat, S. Werth, J. Caro, T. Schiestel, AIChE J. 2010, 127, 2390 - 2396. DOI: 10.1002/aic.12158.

[26] C. Hamel, Á. Tóta, F. Klose, E. Tsotsas, A. Seidel-Morgenstern, Chem. Eng. Res. Des. 2008, 86 (7), 753 - 764. DOI: 10.1016/j.cherd.2008.03.025.

[27] C. Hamel, T. Wolff, P. Subramaniam, A. Seidel-Morgenstern, Ind. Eng. Chem. Res. 2011, 50 (23), 12895 - 12903. DOI: 10.1021/ie2001692. 
[28] C. Hamel, T. Wolff, A. Seidel-Morgenstern, Int. J. Chem. React. Eng. 2011, 9 (1). DOI: 10.1515/1542-6580.2495.

[29] F. Klose, Appl. Catal., A 2004, 260 (1), 101 - 110. DOI: 10.1016/j.apcata.2003.10.005. 